\section{What should I do if I'm asked to work outside of my practice?}

\author{
The covid-19 pandemic has meant that doctors have moved to work in different areas. There are \\ ways to tackle the uncertainty this can bring, Abi Rimmer hears
}

Abi Rimmer

\section{Don't attempt what you cannot do}

Richard Daniels, specialty trainee year 5 in paediatrics, Royal Free NHS Trust, says, "Very few doctors will be able to describe their last year's work as 'normal.' Many of us were redeployed from our usual clinical roles to act as a transient workforce where we were most needed. This is what I have learnt from a unique year.

“Firstly, don't be afraid to say no. Nobody expects you to be comfortable or familiar with work outside your normal scope of practice. As always in medicine, be safe and be honest, and don't attempt what you cannot do. You're more useful delivering a smaller task well than doing a bad job of a bigger one that will then need redoing.

"Think about your skill set. What can you transfer to your new area of work from your usual role that will allow you to be maximally effective? Are there things you can offer to do to free up specialist teams to do work that only they can?

"Don't be afraid to get stuck in wherever you can-senior consultants have done healthcare assistant and nursing shifts in some trusts. Other sites have used extra hands for family liaison roles or for ensuring that all staff can take breaks and have a decent rest and a drink. Help comes in various guises.

“Look at your curriculum. Training doesn't stop just because you're in a different role. What can you reflect on or be assessed on in your temporary role? Education, teamwork, and soft skills are all universal.

"Finally, look after yourself. Working somewhere new is going to be stressful. Recognise that, access appropriate support, and take some time to unwind and reflect."

\section{If in doubt, seek advice}

John Smyth, assistant director of the General Medical Council's case examiner team and former GP, says, "Many, if not all, doctors' roles have adapted to deal with the challenging situation over the past year. Doctors have been doing an incredible job during the pandemic but understandably are worried about the risks they are facing.

"Our advice is to stick to the same basic principles of good practice ${ }^{1}$ and to follow our guidance which advises doctors to recognise and work within the limits of their competence, to use their judgment in applying principles, to assess risk, and deliver safe care.

"Decisions often need to be made quickly but, if in doubt, doctors should seek advice and supervision from colleagues.
"The pressures experienced during the pandemic are unlike those most doctors have experienced before-and the GMC acknowledges doctors may need to be flexible in their approach and sometimes depart from usual procedures.

"If you are faced with working outside your area of practice in an emergency, you should provide the safest care you can. We encourage you to take thorough notes about any concerns that could impact on patient safety and to raise your concerns with your line manager. If you are a trainee ${ }^{2}$ you should seek advice from a supervisor or senior colleague, especially if asked to undertake any work that may be beyond your capabilities.

“All doctors deployed to a different clinical area must receive appropriate induction and training and be aware of who to contact for advice.

"These are extraordinary times and the additional pressures on resources and changes to normal working arrangements have had a significant impact. Doctors can be assured that if a concern ${ }^{3}$ is raised about their practice during the pandemic, the environment in which they were working at the time will always be taken into account. ${ }^{4}$

\section{Raise any concern you may have}

Kathryn Leask, Medical Defence Union (MDU) medico-legal adviser, says, "If you're moved to an unfamiliar clinical area during the pandemic, you should receive an induction, training, and be given an opportunity to familiarise yourself with the new environment.

“To work as safely as possible, engage in additional training to improve your skills and knowledge, such as local or nationally arranged online learning. Have a low threshold for seeking help and advice from senior colleagues and ensure you know how to access support and supervision. This is particularly important for doctors in training who are redeployed to a different speciality.

"Continue to follow GMC guidance as far as practical, such as recognising and working within the limits of your competence. The GMC acknowledges, however, that these are exceptional circumstances and you may find yourself working in unfamiliar settings and at the limits of your comfort zone, or beyond it.

"In an emergency, provide the safest care you can. You have a duty to raise concerns. If patients are being exposed to avoidable risk, inform a senior colleague or manager, and offer your skills and knowledge to find possible solutions. 
"If an incident occurs, it's understandable to have concerns about the consequences. It may be reassuring to know that the GMC accepts the need to depart from established procedures and guidelines on occasion.

“Above all else, look after your own health and wellbeing. Seek support when you need it from your colleagues, family, and friends and, if necessary, your own GP. The MDU or your own medical defence organisation is a good source of support with any medicolegal concerns."

1 GMC. Good medical practice. www.gmc-uk.org/ethical-guidance/ethical-guidance-for-doctors/goodmedical-practice

2 GMC. Supporting the covid-19 response: guidance regarding medical education and training. March 2020. www.gmc-uk.org/news/news-archive/guidance-regarding-medical-education-andtraining-supporting-the-covid-19-response

3 GMC. Covid-19 specific guidance published for doctor complaints. September 2020. www. gmcuk.org/news/news-archive/covid-19-specific-guidance-published-for-doctor-complaints

4 GMC. Joint statement from chief executives of statutory regulators of health and social care professionals. 13 January 2021. www.gmc-uk.org/news/news-archive/joint-statement-from-chiefexecutives-of-statutory-regulators-january-2021

This article is made freely available for use in accordance with BMI's website terms and conditions for the duration of the covid-19 pandemic or until otherwise determined by BMJ. You may use, download and print the article for any lawful, non-commercial purpose (including text and data mining) provided that all copyright notices and trade marks are retained. 